\title{
Caveolin-I overexpression is an early event in the progression of papillary carcinoma of the thyroid
}

\author{
Y Ito*,', H Yoshida', K Nakano', K Kobayashi', T Yokozawa', K Hirai', F Matsuzuka', N Matsuura², \\ K Kakudo ${ }^{3}$, K Kuma' and A Miyauchi'
}

'Department of Surgery, Kuma Hospital, 8-2-35, Shimoyamate-dori, Chuo-ku, Kobe 650-00I I, Japan; '2Department of Pathology, School of Allied Health Science, Osaka University Faculty of Medicine, I-7, Yamadaoka, Suita, Osaka 565-087I, Japan; '3epartment of Pathology, Wakayama Medical School,

Wakayama, Japan

\begin{abstract}
Caveolin-I is a major structural component of caveolae, which are plasma membrane microdomains implicated in the regulation of intracellular signalling pathways. Previous in vitro and in vivo studies on the function of caveolin-I in carcinoma showed controversial results, indicating that the physiological role of caveolin-I varies according to the origin of carcinoma. In this study, we investigated caveolin-I expression in thyroid neoplasms by means of immunohistochemistry using a rabbit polyclonal antibody against caveolin-I. Normal follicular cells did not express caveolin-I. In papillary carcinoma, caveolin-I expression was observed in high incidence, and especially in microcancer (less than $1.0 \mathrm{~cm}$ in diameter), caveolin-I was positive in all cases except one. In undifferentiated (anaplastic) carcinoma, its incidence was significantly reduced. On the other hand, all cases of follicular carcinoma and adenoma were classified as negative for caveolin-I. These results suggest that caveolin-I may play a role predominantly in the early phase of papillary carcinoma, whereas it has little influence on follicular tumours.

British Journal of Cancer (2002) 86, 912-916. DOl: 10.1038/sj/bjc/6600172 www.bjcancer.com

(C) 2002 Cancer Research UK
\end{abstract}

Keywords: caveolin- I; immunohistochemistry; thyroid carcinoma

Caveolin-1 is a $22 \mathrm{kDa}$ protein and a prominent member of the caveolin family. This protein is a major structural component of caveolae, which are the vesicular invaginations of the plasma membrane, and is abundantly present in vascular endothelial cells, adipocytes, smooth muscle cells and fibroblast (Harter and Simons, 1997; Okamoto et al, 1998). Previous studies have demonstrated that the caveolin family contains a common domain, a caveolin-scaffolding domain which organises and concentrates sphingolipids and lipid-modified signalling molecules (Song et al, 1997a). The function of caveolin-1 has been investigated by previous studies, which showed that caveolin-1 inhibits intracellular signal transduction modulated by various signalling molecules (Li et al, 1995; Couet et al, 1997; Garcia-Cardena et al, 1997; Song et al, 1997b; Engelman et al, 1998a; Lui et al, 1999).

The caveolin-1 gene is located at human chromosome 7q31.1, and this region is frequently deleted in carcinomas (Engelman et al, 1998b). The expression of caveolin-1 protein in carcinomas has also been studied. Thus far, a decreased expression of caveolin-1 has been found in a variety of cell lines such as those of breast carcinoma (Lee et al, 1998), lung carcinoma (Racine et al, 1999), sarcoma (Wiechen et al, 2001), uterine cervical carcinoma (Razani et al, 2000), and colon carcinoma (Bender et al, 2000). Furthermore, re-expression of caveolin-1 inhibited the growth of breast carcinoma cells (Lee et al, 1998) and colony formation of sarcoma cells (Razani et al, 2000) and ectopic caveolin-1 expression reduced tumorigenecity of colon carcinoma cells (Bender et al, 2000). These results suggest that the caveolin-1 gene may be a

*Correspondence: Y Ito; E-mail: ito0 I @kuma-h.or.jp Received 30 August 200 I; revised I8 December 200 I; accepted 9 January 2002 candidate as a tumour suppressor gene as its gene product functions as a negative regulator of tumour progression.

On the other hand, the results of studies for caveolin-1 expression using human carcinoma tissue have been different from those using cell lines. Yang et al (1998) showed that the expression of caveolin-1 was elevated in breast and prostate carcinomas and, especially in prostate carcinoma, caveolin- 1 expression was more frequently observed in cases with high biological aggressiveness including poor prognosis (Yang et al, 1999). Furthermore, caveolin-1 expression was more membranous in ovarian carcinoma with short-term survival (Davidson et al, 2001). In colon carcinoma, caveolin-1 expression increased compared to normal epithelium, but it was not linked to the stage (Fine et al, 2001). These results indicate that caveolin-1 has some functions other than as a negative regulator of tumour progression, and its physiological role in carcinoma is complicated depending on the origin of the carcinoma and other various circumstances.

Thyroid carcinoma is one of the most common malignancies originating from the endocrine organs. There are two prominent histological types of thyroid carcinoma originating from the follicular cells. One is papillary carcinoma and the other is follicular carcinoma, which is comparatively rare (LiVolsi and Asa, 1994). Generally, the biological character of these carcinomas is mild, but when they dedifferentiate and become anaplastic (undifferentiated), their growing activity is very strong and patients usually have a dire prognosis, in spite of various therapeutic strategies. These polarised characteristics of thyroid carcinoma have prompted many researchers to study the factors linked to the dedifferentiation of papillary and follicular carcinomas. In this study, we investigated caveolin-1 expression in various types of thyroid neoplasm in order to clarify its role, including this point. 


\section{MATERIALS AND METHODS}

\section{Tissue specimens}

Tissue specimens of thyroid neoplasms were obtained from 161 patients who underwent surgery in the Department of Surgery, Kuma Hospital. These consisted of 32 anaplastic (undifferentiated) carcinomas, 85 papillary carcinomas, 15 widely invasive and eight minimally invasive follicular carcinomas and 11 follicular adenomas. The patients with anaplastic carcinoma were operated on from 1983 to 2001, and those with widely invasive follicular carcinoma from 1995 to 2001. Other cases were selected from patients who underwent surgery from 1999 to 2001. Of the 85 papillary carcinomas, 23 were microcancers which were less than $1.0 \mathrm{~cm}$
A

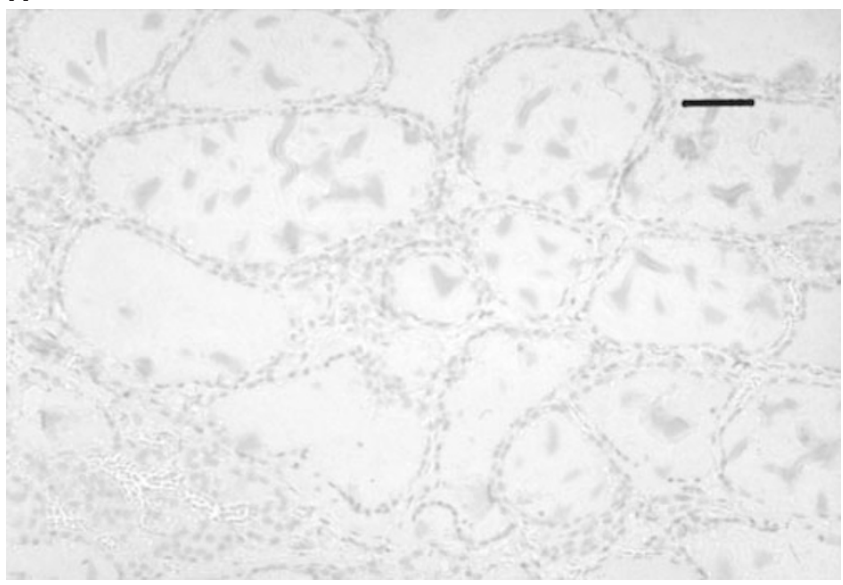

C

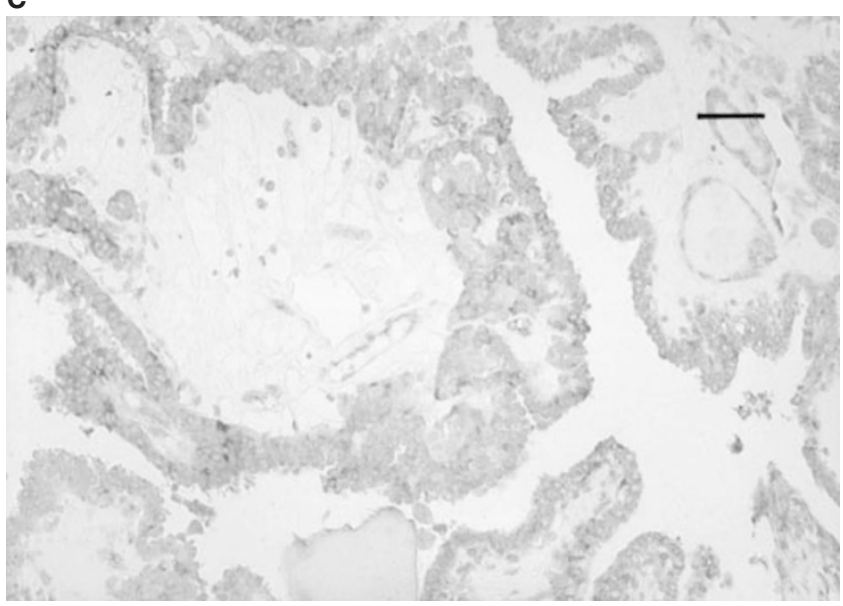

E

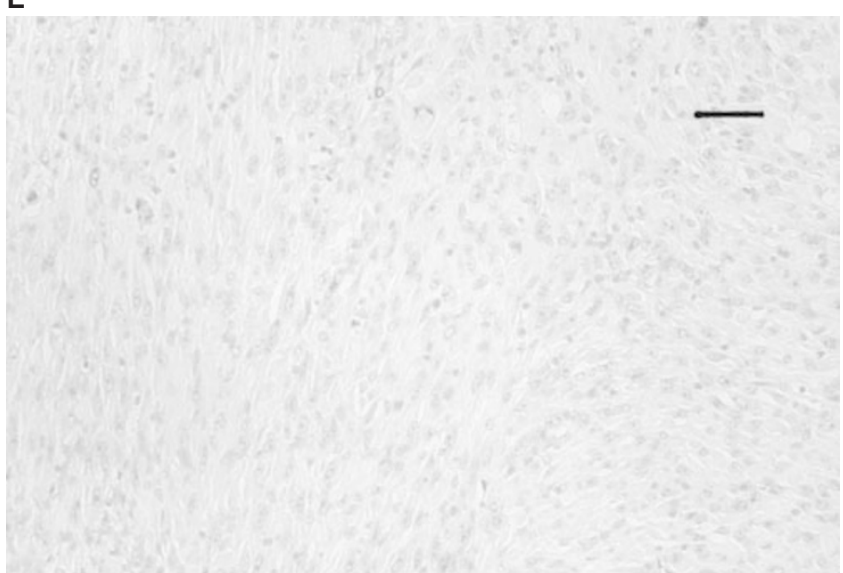

B

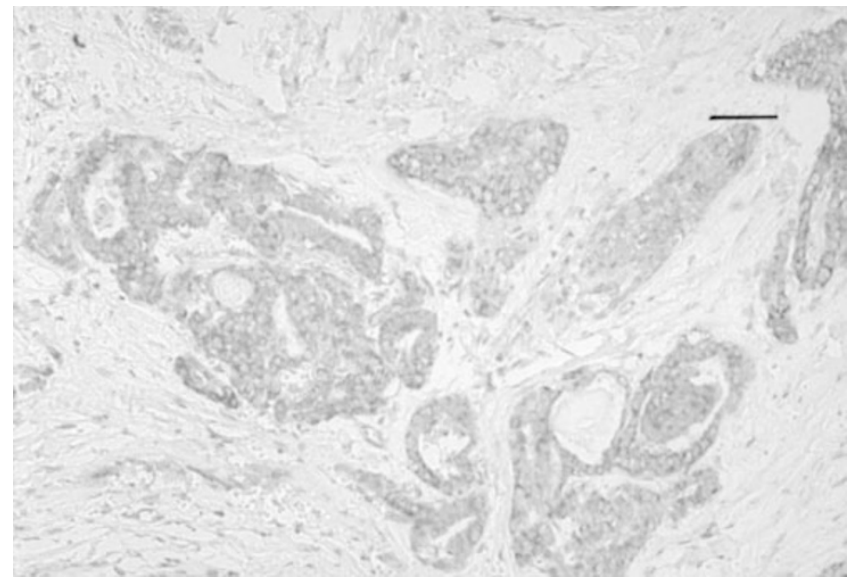

D

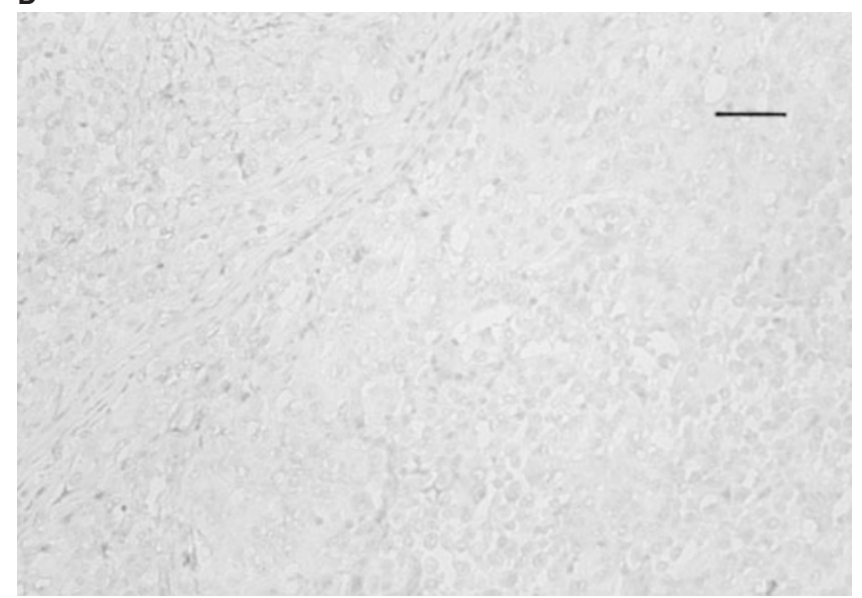

$\mathbf{F}$

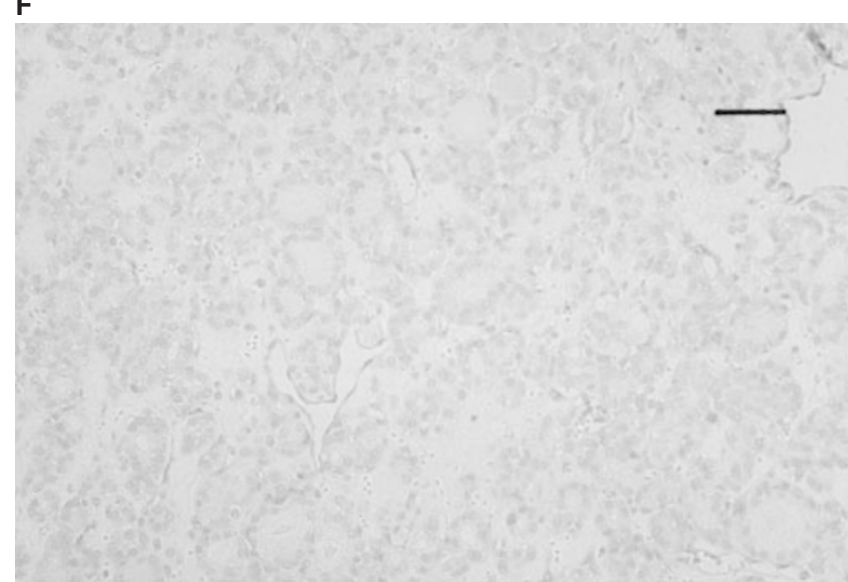

Figure I (A) Caveolin-I is negative in normal follicular cells. (B) Caveolin-I expression in microcancer. This case was classified as (+++). (C) Caveolin-I expression in type A papillary carcinoma classified as $(++)$. (D,E) Caveolin-I is negative in type B papillary $(\mathbf{D})$ and undifferentiated carcinomas (spindle cell type) (E). (F) Caveolin-I is negative in this follicular carcinoma, minimally invasive type. Scale bars, $33 \mu \mathrm{m}$. 
in diameter. They were pre-operatively diagnosed or incidentally found in specimens of other diseases such as hyperthyroidism, adenomatous goiter and follicular adenoma. We divided the remaining papillary carcinoma cases into two categories, type A and type B. Type A papillary carcinoma is composed of pure papillary structure, whereas type B carcinoma has any one of the components showing a solid, trabecular or scirrhous growth pattern. For immunohistochemical study, the tissues were fixed with $10 \%$ formalin and paraffin-embedded. This project was approved by the ethics committees of the hospital and informed consent was obtained from the participating patients.

\section{Antibodies}

We adopted a rabbit polyclonal antibody against caveolin-1 (N-20) at a dilution of 1:300 as the primary antibody, obtained from Santa Cruz Biotechnology (Santa Cruz, CA, USA).

\section{Immunohistochemistry}

Tissue sections $4 \mu \mathrm{m}$ thick were dewaxed and endogenous peroxidase activity was blocked with $0.3 \%$ hydrogen peroxide in methanol for $15 \mathrm{~min}$. After rinsing in distilled water, the sections were then immersed in $0.03 \mathrm{~mol} \mathrm{~L}^{-1}$ citrate buffer ( $\mathrm{pH} \mathrm{6.0)}$ and incubated at $95^{\circ} \mathrm{C}$ for $40 \mathrm{~min}$ in a water bath for antigen retrieval. After rinsing in phosphate-buffered saline pH 7.2 (PBS), 10\% bovine serum (Wako, Osaka, Japan) was applied for $20 \mathrm{~min}$ to block nonspecific reactions. The sections were then incubated with the primary antibody overnight at $4^{\circ} \mathrm{C}$. After rinsing in PBS, they were treated with peroxidase-labelled anti-rabbit immunoglobulins (Nichirei, Tokyo, Japan) for $30 \mathrm{~min}$. The peroxidase reaction was visualised by incubating the sections with $0.02 \% 3,3^{\prime}$-diaminobenzidine tetrahydrochloride in $0.05 \mathrm{M}$ Tris buffer with $0.01 \%$ hydrogen peroxide (Nichirei, Tokyo, Japan). The sections were counterstained with haematoxylin. Sections for the negative control were prepared using rabbit immunoglobulins instead of the primary antibody.

\section{Immunohistochemical evaluation}

We regarded cells as immunoreactive when the staining signal was clearly observed in their cytoplasms. We scored immunoreacitivity as follows: $(-)$ less than $10 \%$ of cells were immunoreactive; $(+)$ $10-25 \%$ of cells were immunoreactive; $(++) 25-50 \%$ of cells were immunoreactive, and $(+++)$ more than $50 \%$ of cells were immunoreactive. The $(++)$ and $(+++)$ cases were considered as positive for caveolin-1.

\section{Statistical analyses}

Chi-square analysis was employed to analyse the relationship between caveolin-1 expression and the pathological classification of thyroid neoplasms. A $P$ value of less than 0.05 was considered to be statistically significant.

\section{RESULTS}

Caveolin-1 immunoreactivity was frequently present in the endothelial cells in blood vessels in the stroma, which were recognised as an internal positive control. Follicular cells of normal thyroid tissue did not express caveolin-1 (Figure 1A). We then investigated caveolin-1 expression in various types of thyroid neoplasm (Table 1). Of the 85 papillary carcinomas, 57 cases (67.1\%) were judged as positive for caveolin-1. Especially in microcancers, caveolin-1 was positive in all the cases except one (Figure 1B). Of the remaining two types of papillary carcinoma, cases with a pure papillary structure, classified as type A, were more frequently positive than those with other growth patterns (type
Table I Expression of caveolin-I in thyroid neoplasms

\begin{tabular}{|c|c|c|c|c|c|}
\hline \multirow{3}{*}{$\begin{array}{l}\text { Caveolin-I } \\
\text { immunoreactivity }\end{array}$} & \multicolumn{4}{|c|}{ Caveolin-I expression } & \multirow[b]{3}{*}{ Tota } \\
\hline & \multicolumn{2}{|c|}{ Negative } & \multicolumn{2}{|c|}{ Positive } & \\
\hline & - & + & ++ & +++ & \\
\hline $\begin{array}{l}\text { Anaplastic (undifferentiated } \\
\text { carcinoma) }\end{array}$ & 20 & 8 & 2 & 2 & 32 \\
\hline Type B papillary carcinoma & | | & 8 & 7 & 5 & 31 \\
\hline Type A papillary carcinoma & 2 & 6 & 10 & 13 & 31 \\
\hline Microcancer & 0 & I & 6 & 16 & 23 \\
\hline $\begin{array}{l}\text { Widely invasive follicular } \\
\text { carcinoma }\end{array}$ & 15 & 0 & 0 & 0 & 15 \\
\hline $\begin{array}{l}\text { Minimally invasive follicular } \\
\text { carcinoma }\end{array}$ & 18 & 0 & 0 & 0 & 18 \\
\hline Follicular adenoma & 11 & 0 & 0 & 0 & | | \\
\hline
\end{tabular}

$P=0.0169$ (anaplastic carcinoma vs type B papillary carcinoma); $P=0.0048$ (type $B$ papillary carcinoma vs type A papillary carcinoma); $P=0.0364$ (type A papillary carcinoma vs microcancer)

B) (Figure 1C,D). In anaplastic (undifferentiated) carcinomas, only four cases $(12.5 \%)$ were positive for caveolin-1, which was significantly lower than in type B papillary carcinomas (Figure 1E).

We also examined caveolin-1 expression in tumours of follicular type, that is, 11 cases of follicular adenoma, 18 cases of minimally invasive follicular carcinoma and 15 cases of widely invasive follicular carcinoma. However, in contrast to the papillary carcinomas, caveolin-1 immunoreactivity was not seen in the tumour cells of these tissues, and all these cases were classified as negative, regardless of histological type (Figure 1F).

\section{DISCUSSION}

In this study, we have demonstrated that caveolin-1 was frequently positive in papillary carcinoma, but not in tumours of the follicular type. In papillary carcinomas, caveolin-1 was more frequently positive in microcancers than those of larger size, indicating that caveolin-1 expression is an early event in papillary carcinoma. An additional more important finding is that caveolin-1 expression significantly decreased in undifferentiated (anaplastic) carcinomas. Anaplastic carcinomas can arise from follicular carcinoma as well as papillary carcinoma, but most are thought to be from papillary carcinoma, because papillary carcinoma is far more common than follicular carcinoma. These results allow us to hypothesise that, in papillary carcinoma, caveolin-1 works as a negative regulator of carcinoma progression and the lack of or decreased expression of this protein is linked to the increase in biological aggressiveness. The reduced expression of caveolin-1 in type B carcinomas compared to type A carcinomas is also reasonable because cases with type B histology were reported to show a poorer prognosis than pure papillary carcinomas (type A), although it is still an open question whether type B cases actually represent dedifferentiation as proposed by Sakamoto et al (1983).

The function of caveolin-1 has been intensively investigated by many researchers. Engelman et al (1998b) have demonstrated that caveolin-1 negatively regulates the activity of p42/44 MAP kinase, with the result that caveolin-1 dramatically inhibits signalling from EGF-R, Raf, MEK-1 and ERK-2 to the nucleus. Furthermore, similar relationships were observed between caveolin-1 and heterotrimeric G proteins ( $\mathrm{Li}$ et al, 1995), c-Src tyrosine kinase (Song et al, 1997b) and nitric oxide synthase (Garcia-Cardena et al, 1997), and all these phenomena are mediated through the caveolin-scaffolding domain. Similar results have also been obtained for signal transduction from c-erbB-2 (Engelman et al, 1998c) and vascular endothelial growth factor receptor (VEGF-R) (Lui et al, 1999). As EGF-R (van der Laan et al, 1995), VEGF and VEGF-R (Klein et al, 1999) as well as c-erbB-2 (Utrilla et al, 
1999) are known to be frequently present in papillary carcinoma, these data support the above hypothesis. In contrast, the aberrant expression of c-erbB-2, VEGF, basic FGF and hepatocyte growth factors, as well as inactivation of p53, can, in turn, down-regulate caveolin-1 (Engelman et al, 1998c; Lui et al, 1999; Razani et al, 2000). Furthermore, when EGF-R binds to EGF, it can move out of the caveolae with the modulation of Src kinase (Mineo et al, 1999). It is therefore suggested that the abundant expression of various growth factors and the inactivation of tumour suppressor genes, such as p53, may cause the down-regulation or decreased expression of caveolin-1. Regarding the molecular mechanism of down-regulation of caveolin-1, Cui et al (2001), have reported hypermethylation of the caveolin-1 gene promoter in prostate carcinoma and also, mutation of the caveolin-1 gene has been identified in scirrhous breast carcinomas (Hayashi et al, 2001). Further studies of this subject should be carried out on various carcinomas.

On the other hand, caveolin-1 is phosphorylated at tyrosin-14 by $\mathrm{c}$-Src kinase and binds to growth factor receptor-binding protein 7 , which results in anchorage-independent growth and EGF-stimulated cell migration (Lee et al, 2000). This indicates the possibility that caveolin-1 not only inhibits but also stimulates carcinoma progression and metastasis. In prostate carcinoma, Yang et al (1999) have demonstrated that caveolin-1 expression is directly related to the Gleason score, positive surgical margin and lymph node metastasis, and it independently predicts a worse prognosis for patients. They also showed that caveolin- 1 can be secreted

\section{REFERENCES}

Bender FC, Reymond MA, Bron C, Quest AF (2000) Caveolin-1 levels are down-regulated in human colon tumors, and ectopic expression of caveolin-1 in colon carcinoma cell lines reduces cell tumorigenecity. Cancer Res 60: $5870-5878$

Couet J, Sargiacomo M, Lisanti MP (1997) Interaction of a receptor tyrosine kinase, EGF-R, with caveolins. Caveolin binding negatively regulates tyrosine and serine/threonine kinase activities. J Biol Chem 272: 30429-30438

Cui J, Rohr LR, Swanson G, Speights VO, Maxwell T, Brothman AR (2001) Hypermethylation of the cavolin-1 gene promoter in prostate cancer. Prostate 46: $246-256$

Davidson B, Nesland JM, Goldberg I, Kopolovic J, Gotlieb WH, Bryne M, Ben-Baruch G, Berner A, Reich R (2001) Caveolin-1 expression in advanced-stage ovarian carcinoma-a clinicopathological study. Gynecol Oncol 81: 166-171

Engelman JA, Chu C, Lin A, Jo H, Ikezu T, Okamoto T, Kohtz DS, Lisanti MP (1998a) Caveolin-mediated regulation of signaling along the p42/44 MAP kinase cascade in vivo. A role for the caveolin-scaffolding domain. FEBS Lett 428: 205-211

Engelman JA, Zhang XL, Lisanti MP (1998b) Genes encoding human caveolin- 1 and -2 are co-localized to the D7S522 locus (7q31.1), a known fragile site (FRA7G) that is frequently deleted in human cancers. FEBS Lett 436: $403-410$

Engelman JA, Lee RJ, Karnezis A, Bearss DJ, Webster M, Siegel P, Muller WJ, Windle JJ, Pestell RG, Lisanti MP (1998c) Reciprocal regulation of neu tyrosine kinase activity and caveolin-1 protein expression in vitro and in vivo. Implications for human breast cancer. J Biol Chem 273: $20448-$ 20455

Fine SW, Lisanti MP, Galbiati F, Li M (2001) Elevated expression of caveolin1 in adenocarcinoma of the colon. Am J Clin Pathol 115: 719-724

Garcia-Cardena G, Martasek P, Masters BS, Skidd PM, Couet J, Li S, Lisanti MP, Sessa WC (1997) Dissecting the interaction between nitric oxide synthase (NOS) and caveolin. Functional significance of the nos caveolin binding domain in vivo. J Biol Chem 272: 25427-25440

Harter T, Simons K (1997) Caveolae, DIGs, and dynamics of sphingolipidcholesterol microdomains. Curr Opin Cell Biol 9: 534-542

Hayashi K, Matsuda S, Machida K, Yamamoto T, Fukuda Y, Nimura Y, Hayakawa T, Hamaguchi M (2001) Invasion activating caveolin-1 mutation in human scirrhous breast cancers. Cancer Res 61: 2361-2364

Klein M, Picard E, Vignaud JM, Marie B, Bresler L, Tousssaint B, Weryha G, Duprez A, Leclere J (1999) Vascular endothelial growth factor gene and protein: strong expression in thyroiditis and thyroid carcinoma. J Endcrinol 161: $41-49$ and can contribute to metastasis in androgen-insensitive prostate carcinoma in an autocrine/paracrine fashion (Tahir et al, 2001). It is therefore suggested that the function of caveolin-1 is not uniform in carcinoma, depending on the origin of the carcinoma and on the expression status of various growth factors and hormones. Studies regarding the secreted type of caveolin-1 in thyroid carcinoma will be necessary in the future.

Interestingly, in follicular tumours, no caveolin-1 expression was observed in any cases, regardless of histological type. It is therefore suggested that the regulation of caveolin-1 does not act on or against the progression of follicular tumours. As there is no striking difference between the prognosis of patients with follicular carcinoma and papillary carcinoma, regulation of some other type than caveolin-1 must operate for signal transduction in follicular carcinomas. A previous study observed that c-erbB-2 oncoprotein was expressed in more than $50 \%$ of papillary carcinomas but not in follicular carcinomas or undifferentiated carcinomas (Utrilla et al, 1999). The difference in the status of these proteins in papillary and follicular carcinomas reflects the difference of entities between these two types of carcinoma.

In summary, this study indicates that, in papillary carcinomas, caveolin-1 plays a role in the early phase and its decreased expression is linked to aggressive characteristics including dedifferentiation. Further studies should be carried out regarding the mechanism of function and/or the lack of function of caveolin-1 in thyroid carcinoma.
Lee H, Volonte D, Galbiati F, Lyengar P, Lublin DM, Bregman DB, Wilson MT, Campls-Gonzalez R, Bouzahzah B, Pestell RG, Scherer PE, Lisanti MP (2000) Constitutive and growth factor-regulated phosphorylation of caveolin-1 occurs at the same site (Tyr-14) in vivo: identification of a cSrc/Cav-1/Grb7 signaling cassette. Mol Endocrinol 14: 1750-1755

Lee SW, Reimer CL, Oh P, Campbell DB, Schnitzer JE (1998) Tumor cell growth inhibition by caveolin reexpression in human breast cancer cells. Oncogene 16: 1391-1397

Li S, Okamoto T, Chun M, Sargiacomo M, Casanova JE, Hansen SH, Nishimoto I, Lisanti MP (1995) Evidence for a regulated interaction between heterotrimeric G proteins and caveolin. J Biol Chem 270: 15693-15701

LiVolsi VA, Asa SL (1994) The demise of follicular carcinoma of the thyroid gland. Thyroid 4: $233-237$

Lui J, Razani B, Tang S, Terman BI, Ware JA, Lisanti MP (1999) Angiogenesis activator and inhibitors differentially regulate caveolin-1 expression and caveolae formation in vascular endothelial cells. Angiogenesis inhibitors block vascular endothelial growth factor-induced down-regulation of caveolin-1. J Biol Chem 274: $15781-15785$

Mineo C, Gill GN, Anderson RG (1999) Regulated migration of epidermal growth factor receptor from caveolae. J Biol Chem 274: 30636-30643

Okamoto T, Schlegel A, Scherer PE, Lisanti MP (1998) Caveolins, a family of scaffolding proteins for organizing "preassembled signaling complexes" at the plasma membrane. J Biol Chem 273: 5419-5422

Racine C, Belanger M, Hirabayashi H, Boucher M, Chakir J, Couet J (1999) Reduction of caveolin 1 gene expression in lung carcinoma cell lines. Biochem Biophys Res Commun 255: 580-586

Razani B, Altschuler Y, Zhu L, Pestell RG, Mostov KE, Lisanti MP (2000) Caveolin-1 expression is down-regulated in cells transformed by the human papilloma virus in a p53-dependent manner. Replacement of caveolin-1 expression suppresses HPV-mediated cell transformation. Biochemistry 39: $13916-13924$

Sakamoto A, Kasai N, Sugano H (1983) Poorly differentiated carcinoma of the thyroid. A clinicopathologica entity for a high-risk group of papillary and follicular carcinomas. Cancer 52: 1849-1855

Song K, Tang Z, Li S, Lisanti MP (1997a) Mutational analysis of the properties of caveolin-1: a novel role for the C-terminal domain in mediating homotypic caveolin-caveolin interactions. J Biol Chem 272: 4398-4403

Song KS, Sargiacomo M, Galbiati F, Parenti M, Lisanti MP (1997b) Targeting of a G alpha subunit (Gil alpha) and c-Src tyrosin kinase to caveolae membranes: clarifying the role of N-myristoylation. Cell Mol Biol 43: $293-303$ 
Tahir SA, Yang G, Ebara S, Timme TL, Satoh T, Li L, Goltsov A, Ittmann M, Morriset JD, Thompson TC (2001) Secreted caveolin-1 stimulates cell survival/clonal growth and contributes to metastasis in androgen-insensitive prostate cancer. Cancer Res 61: $3882-3885$

Utrilla JC, Martin-Lacave I, San Martin MV, Fernandez-Santos JM, GaleraDavidson H (1999) Expression of c-erbB-2 oncoprotein in human thyroid tumours. Histopathology 35: 60-65

van der Laan BF, Freeman JL, Asa SL (1995) Expression of growth factors and growth factor receptors in normal and tumorous human thyroid tissues. Thyroid 5: $67-73$

Wiechen K, Sers C, Agoulnik A, Arlt K, Dietel M, Schlag PM, Schneider U (2001) Down-regulation of caveolin-1, a candidate tumor suppressor gene, in sarcomas. Am J Pathol 158: 833-839

Yang G, Truong L, Timme TL, Ren C, Wheeler TM, Park SH, Nasu Y, Bangma CH, Kattan MW, Scardino PT, Thompson TC (1998) Elevated expression of caveolin is associated with prostate and breast cancer. Clin Cancer Res 4: $1873-1880$

Yang G, Truong LD, Wheeler TM, Thompson TC (1999) Caveolin-1 expression in clinically confined human prostate cancer: a novel prognostic marker. Cancer Res 59: 5719-5723 